\title{
In-stent restenosis-prone coronary plaque composition: A retrospective virtual histology-intravascular ultrasound study
}

\author{
Duck-Jun Seo ${ }^{1}$, Yong-Kyun Kim ${ }^{1}$, Young-Hoon Seo ${ }^{1}$, In-Geol Song ${ }^{1}$, \\ Ki-Hong Kim ${ }^{1}$, Taek-Geun Kwon ${ }^{1}$, Hyun-Woong Park ${ }^{2}$, Jang-Ho Bae ${ }^{1}$ \\ ${ }^{1}$ Cardiology, Konyang University Hospital, Daejeon, South Korea \\ ${ }^{2}$ Department of Cardiology, Gyeongsang National University Hospital, Jinju, South Korea
}

\begin{abstract}
Background: The mechanism of in-stent restenosis (ISR) is multifactorial, which includes biological, mechanical and technical factors. This study hypothesized that increased inflammatory reaction, which is known to be an important atherosclerotic process, at a culprit lesion may lead to higher restenosis rates.
\end{abstract}

Methods: The study population consisted of 241 patients who had undergone percutaneous coronary intervention with virtual histology-intravascular ultrasound (VH-IVUS) and a 9-month follow-up coronary angiography. Compared herein is the coronary plaque composition between patients with ISR and those without ISR.

Results: Patients with ISR $(n=27)$ were likely to be older $(66.2 \pm 9.5$ years vs. $58.7 \pm 11.7$ years, $p=0.002$ ) and have higher levels of high-sensitivity $C$-reactive protein (hs-CRP, $1.60 \pm 3.59 \mathrm{mg} / \mathrm{dL}$ vs. $0.31 \pm 0.76 \mathrm{mg} / \mathrm{dL}, p<0.001)$ than those without ISR $(n=214)$. VH-IVUS examination showed that percent necrotic core volume $(14.3 \pm 8.7 \%$ vs. $19.5 \pm 9.1 \%, p=0.005)$ was higher in those without ISR than those with ISR. Multivariate analysis revealed that hs-CRP (odds ratio [OR] 3.334, 95\% confidence interval [CI] 1.158-9.596, $p=0.026)$ and age (OR 3.557, 95\% CI 1.242-10.192, $p=0.018)$ were associated with ISR.

Conclusions: This study suggests that ISR is not associated with baseline coronary plaque composition but is associated with old age and increased expression of the inflammatory marker of hs-CRP.

(Cardiol J 2018; 25, 1: 7-13)

Key words: intravascular ultrasonography, coronary artery disease, myocardial ischemia, inflammation, coronary stenosis

\section{Introduction}

Over recent decades, percutaneous coronary intervention (PCI) techniques have improved extraordinarily. In particular, the introduction of the drug-eluting stent (DES) reduced the prevalence of in-stent restenosis (ISR) and the re-intervention rate compared to the bare-metal stent. Rates of target lesion revascularization were as high as $20 \%$ with the bare metal stent compared to the single-digit rates with DES $[1,2]$. However, despite the extensive introduction of DESs, ISR did not disappear and is still causing problems in high-risk patients and complex lesions [3-5].

The mechanisms involved in ISR include biological, mechanical, and technical factors. The mechanical and technical factors related to ISR can be overcome by using new-generation polymer-free DESs, intracoronary imaging and/or high-pressure ballooning, which eliminate stent malapposition,

Address for correspondence: Jang-Ho Bae, MD, PhD, Heart Center, Konyang University Hospital, 158, Gwanjeodong-ro, Seo-Gu, Daejeon, South Korea, 35365, e-mail: janghobae@yahoo.co.kr 
total lesion coverage, and stent edge dissection. Inflammation, which is an important mechanism of atherosclerosis, is also known as an important factor in the restenosis process. The inflammatory process includes platelet deposition, leukocyte recruitment, and smooth muscle cell migration and proliferation [6, 7]. These inflammatory processes were seen in human and rabbit models after stenting. Inflammation after stenting in human was more profound in damaged media in contact with the stent. In addition, the inflammatory cytokine CD 11b was increased in patients with restenosis [8].

Therefore, we hypothesized that a greater inflammatory reaction at the culprit lesion may lead to higher restenosis rates. The objective of this study was to compare plaque composition, which represents plaque inflammatory status, in patients with ISR and those without ISR.

\section{Methods}

\section{Study population}

The study population consisted of 331 consecutive patients of PCI and virtual histology-intravascular ultrasound (VH-IVUS) at the Konyang University Hospital. Ninety patients were excluded because they did not undergo the 9-month followup coronary angiography (CAG) mainly due to no subjective symptoms and inconvenience. A total of 241 patients who underwent $\mathrm{PCI}$ with stenting and VH-IVUS as well as the 9-month follow-up CAG were enrolled in this study. An ISR was defined as the presence of over $50 \%$ diameter stenosis by visual assessment in the stented lesion [9]. Twenty-seven $(11.2 \%)$ patients had ISR, whereas $214(88.8 \%)$ patients showed no ISR. The angiographic findings were reviewed by two blinded cardiologists. Another cardiologist gave an opinion if the 2 cardiologists disagreed about the ISR.

Demographic data of the study population were confirmed by chart review. Coronary risk factors included hypertension (blood pressure $\geq 140 / 90 \mathrm{~mm} \mathrm{Hg}$ based on the average of repeated readings or the presence of antihypertensive drug therapy), dyslipidemia (total cholesterol $>200 \mathrm{mg} / \mathrm{dL}$ and/or triglyceride $>150 \mathrm{mg} / \mathrm{dL}$ and/or low-density lipoprotein cholesterol $>130 \mathrm{mg} / \mathrm{dL}$ or patients on lipid-lowering therapy), diabetes mellitus (controlled with diet, oral hypoglycemic agents, or insulin, fasting glucose levels $\geq 126 \mathrm{mg} / \mathrm{dL}$, or $2 \mathrm{~h}$ oral glucose tolerance test $\geq 200 \mathrm{mg} / \mathrm{dL}$ ), and current cigarette smoking. This study was approved by the ethics committee of the Konyang University
Hospital and was in accordance with the Declaration of Helsinki.

\section{PCI}

All patients received $300 \mathrm{mg}$ aspirin, 300-600 $\mathrm{mg}$ clopidogrel, and $120 \mathrm{IU} / \mathrm{kg}$ of unfractionated heparin intravenously before PCI. PCI was performed via the radial or femoral approach using 5 , 6 or $7 \mathrm{Fr}$ guiding catheter and 0.014-inch standard or extra-support coronary guidewires. The culprit lesion was identified by ventricular wall motion abnormalities and the appearance of the angiographic lesion. All study subjects underwent successful $\mathrm{PCI}$ at the culprit lesion and VH-IVUS examination.

\section{IVUS examination and analysis}

VH-IVUS examination was performed on the culprit lesion with a dedicated $20-\mathrm{MHz}, 2.9 \mathrm{~F}$ monorail, electronic Eagle Eye Gold IVUS catheter (Volcano Therapeutics, Rancho Cordova, California) and VH-IVUS console (Volcano Therapeutics, Rancho Cordova, California) during the CAG after intracoronary administration of $100-200 \mu \mathrm{g}$ nitroglycerin. The IVUS catheter was advanced into the target lesion after wiring or ballooning and an automatic pullback at $0.5 \mathrm{~mm} / \mathrm{s}$ was done. The VH-IVUS image was recorded on a DVD-ROM for offline analysis.

Both qualitative and quantitative analyses of grayscale IVUS images were performed according to the criteria of the American College of Cardiology's Clinical Expert Consensus Document on IVUS [10-12]. The proximal and distal references were defined as the sites with the largest lumen that were proximal and distal to the stenosis but within the same segment (usually within $10 \mathrm{~mm}$ of the stenosis with no major intervening branches), respectively.

The cross-sectional area (CSA) of the external elastic membrane (EEM) was measured with customized software (IVUS lab., Volcano Therapeutics, Rancho Cordova, CA, USA). The remodeling index was calculated as the lesion EEM CSA divided by the average reference EEM CSA.

\section{Spectral analysis of the IVUS radiofrequency data}

The following analyses were conducted on the target lesion with customized software (IVUS Lab.; Volcano Therapeutics, Rancho Cordova, California) by an examiner who was unaware of the grayscale IVUS results. For both the lumen and the mediaadventitia interface, automatic border detection 
was done at the predefined lesion segment. The border detection was manually corrected in the lesion after automatic border detection. Border detection required the agreement of two independent experienced cardiologists (KTG and PHW). Disagreements were reviewed by a third cardiologist (BJH). After confirming the border detection, the software automatically calculated and showed the results. For each frame, the histologic findings were expressed in colors (green for fibrous, green-yellow for fibro-fatty, white for dense calcified, and red for necrotic core area). The predictive accuracy of this method with tissue mapping has been validated [13]. The area $\left(\mathrm{mm}^{2}\right)$ and percent area of each tissue component of the plaque were analyzed at the minimal luminal area site, and the volume $\left(\mathrm{mm}^{3}\right)$ and the percent volume of each tissue component of the plaque were evaluated at a full segment of the culprit lesion. Volume was divided by lesion length to adjust for the different lesion lengths of each patient, and this was reported as the corrected volume $\left(\mathrm{mm}^{3} / \mathrm{mm}\right)$.

\section{Statistical analysis}

All analyses were performed with SPSS (version 18.0; SPSS Inc., Chicago, Illinois). All data were expressed as the mean \pm standard deviation for continuous variables and as percentage ratios for categorical variables. Categorical variables were compared by the $\chi^{2}$ test. Continuous variables were compared by independent t-tests. Binary logistic regression analyses were performed to determine the independent factors for ISR. A p value $<0.05$ was considered statistically significant.

\section{Results}

\section{Demographics}

The patients with ISR $(\mathrm{n}=27,11.2 \%)$ were likely to be older $(66.2 \pm 9.5$ years old vs. $58.7 \pm$ \pm 11.7 years old, $\mathrm{p}=0.002$ ) and have higher highsensitivity C-reactive protein (hs-CRP) expression $(1.60 \pm 3.59 \mathrm{mg} / \mathrm{dL}$ vs. $0.31 \pm 0.76 \mathrm{mg} / \mathrm{dL}$, $\mathrm{p}<0.001)$ than those without ISR $(\mathrm{n}=214,88.8 \%)$. In addition, patients with ISR were more likely to take beta-blockers $(88.9 \%$ vs. $70.0 \%, p=0.046)$ than those without ISR. Other demographic findings, such as risk factors, medication and other blood chemistry, showed no significant differences between the two groups (Table 1).

Angiographic findings also showed no significant differences between the two groups in terms of treated vessel, inserted stent type, length and diameter (Table 2).

\section{IVUS findings}

Grayscale IVUS findings also showed no significant differences between the two groups (Table 3 ). Baseline volumetric VH-IVUS findings over the lesion length showed smaller necrotic core volume $\left(14.2 \pm 12.7 \mathrm{~mm}^{3}\right.$ vs. $\left.22.1 \pm 19.9 \mathrm{~mm}^{3}, \mathrm{p}=0.045\right)$ and percent necrotic core volume $(14.3 \pm 8.7 \%$ vs. $19.5 \pm 9.1 \%, \mathrm{p}=0.005)$ in patients with ISR compared to those without ISR by univariate analysis. However, percent fibrofatty volume was larger $(16.6 \pm 9.7 \%$ vs. $12.4 \pm 8.4 \%, \mathrm{p}=0.018)$ by univariate analysis in patients with ISR than in those without ISR. Baseline lesion analysis at the minimal luminal area showed no significant differences between the two groups (Table 4). Fibrocalcific atheroma was the most frequent lesion type $(\mathrm{n}=10,37.0 \%)$ in patients with ISR, whereas thin cap fibroatheroma ( $\mathrm{n}=103,48.1 \%)$ was the most common type in those without ISR.

\section{Independent factors for ISR}

Binary logistic regression analyses showed that the VH-IVUS findings did not have any significant impact on ISR rates in this study population. When we performed the analysis in those with acute coronary syndrome and those with stable angina, there were no significant factors for ISR. Old age and higher hs-CRP were the significant independent factors for ISR in this study (Table 5).

\section{Discussion}

The main findings of this study are as follows: first, old age and high inflammatory status, which was reflected by a high serum hs-CRP level, were associated with ISR in patients with DES implantation; second, baseline plaque composition did not have an impact on ISR in patients in the present study.

Introduction of the DES significantly reduced ISR due to the anti-inflammatory, immunomodulatory, and/or antiproliferative actions of coated drugs. However, ISR is still a major limitation of DESs, which is caused by biological (drug resistance and hypersensitivity), mechanical (stent underexpansion, nonuniform drug distribution, and stent fracture), and technical factors (barotraumas outside stented segment, stent gap, and residual uncovered atherosclerotic plaques) [6]. A study showed that inflammatory cytokine-associated neointimal hyperplasia resulted in granuloma formation and reactive inflammatory infiltration, which is a main etiology of ISR in stented vessels in the pig coronary restenosis model [14]. Inflammatory 
Table 1. Baseline patient demographics.

\begin{tabular}{|c|c|c|c|}
\hline & $\operatorname{ISR}(+) ; n=27(11.2 \%)$ & ISR (-); n = $214(88.8 \%)$ & $\mathbf{P}$ \\
\hline \multicolumn{4}{|l|}{ Characteristics: } \\
\hline Age [years] & $66.2 \pm 9.5$ & $58.7 \pm 11.7$ & 0.002 \\
\hline Male & $16(59.3 \%)$ & $156(72.9 \%)$ & 0.140 \\
\hline Ejection fraction [\%] & $66.2 \pm 9.7$ & $62.8 \pm 10.3$ & 0.113 \\
\hline Old MI & $3(11.1 \%)$ & $8(3.7 \%)$ & 0.084 \\
\hline Stable angina & $19(70.4 \%)$ & $114(53.3 \%)$ & 0.092 \\
\hline ACS & $8(29.6 \%)$ & $100(46.7 \%)$ & 0.092 \\
\hline Unstable angina & $3(11.1 \%)$ & $21(9.8 \% \%)$ & \\
\hline NSTEMI & $2(7.4 \%)$ & $15(7.0 \%)$ & \\
\hline STEMI & $3(11.1 \%)$ & $64(29.9 \%)$ & \\
\hline \multicolumn{4}{|l|}{ Risk factors: } \\
\hline Current smoking & $7(25.9 \%)$ & $87(40.7 \%)$ & 0.130 \\
\hline Diabetes & $11(40.7 \%)$ & $55(25.7 \%)$ & 0.105 \\
\hline Hypertension & $18(66.7 \%)$ & $111(51.9 \%)$ & 0.160 \\
\hline Dyslipidemia & $6(22.2 \%)$ & $81(37.9 \%)$ & 0.126 \\
\hline \multicolumn{4}{|l|}{ Medications: } \\
\hline Aspirin & $27(100 \%)$ & $211(98.6 \%)$ & 0.721 \\
\hline Statins & $22(81.5 \%)$ & $192(89.7 \%)$ & 0.146 \\
\hline ACEI & $16(59.3 \%)$ & $134(62.6 \%)$ & 0.689 \\
\hline ARB & $1(3.7 \%)$ & $22(10.3 \%)$ & 0.268 \\
\hline BB & $24(88.9 \%)$ & $150(70.0 \%)$ & 0.046 \\
\hline CCB & $2(7.4 \%)$ & $24(11.2 \%)$ & 0.539 \\
\hline $\mathrm{OHA}$ & $9(33.3 \%)$ & $41(19.1 \%)$ & 0.092 \\
\hline Insulin & $0(0 \%)$ & $7(3.3 \%)$ & 0.338 \\
\hline \multicolumn{4}{|l|}{ Laboratory: } \\
\hline Total cholesterol [mg/dL] & $183 \pm 42$ & $194 \pm 56$ & 0.324 \\
\hline Triglyceride $[\mathrm{mg} / \mathrm{dL}]$ & $174 \pm 105$ & $174 \pm 145$ & 0.988 \\
\hline HDL cholesterol [mg/dL] & $41.5 \pm 9.8$ & $44.3 \pm 10.7$ & 0.207 \\
\hline LDL cholesterol [mg/dL] & $121 \pm 30$ & $125 \pm 33$ & 0.515 \\
\hline Creatinine $[\mathrm{mg} / \mathrm{dL}]$ & $1.06 \pm 0.24$ & $1.00 \pm 0.21$ & 0.162 \\
\hline hs-CRP [mg/dL] & $1.60 \pm 3.59$ & $0.31 \pm 0.76$ & $<0.000$ \\
\hline \multicolumn{4}{|l|}{ At the time of FU CAG: } \\
\hline Death & $0(0 \%)$ & $0(0 \%)$ & \\
\hline Ischemic driven & $11(40.7 \%)$ & $27(12.6 \%)$ & $<0.000$ \\
\hline Acute MI & $4(14.8 \%)$ & $0(0 \%)$ & $<0.000$ \\
\hline Repeat PCl & $13(48.1 \%)$ & $0(0 \%)$ & $<0.000$ \\
\hline
\end{tabular}

ISR - in-stent restenosis; MI - myocardial infarction; ACS - acute coronary syndrome; NSTEMI — non-ST-elevation myocardial infarction; STEMI - ST-elevation myocardial infarction; ACEI — angiotensin-converting enzyme inhibitors; ARB - angiotensin receptor blockers; BB beta-blockers; CCB — calcium channel blockers; OHA — oral hypoglycemic agents; HDL — high-density lipoprotein; LDL — low-density lipoprotein; hs-CRP — high-sensitivity C-reactive protein; FU CAG — follow-up coronary angiography; $\mathrm{PCl}$ - percutaneous coronary intervention

reaction is also important in ISR in humans. Inflammatory reaction after coronary stenting leads to vascular injury, and secondary inflammation activates smooth muscle cells to transform, migrate, and proliferate, ultimately inducing neointima formation, which contributes to coronary ISR [15].
A recent study has also shown the association of higher and more-prolonged CRP plasma levels and ISR [16]. Moreover, the degree of initial coronary plaque inflammation, which was reflected by hs-CRP level, associated with coronary in-stent restenosis after PCI in recurrent unstable angina. 
Table 2. Baseline angiographic and procedural findings.

\begin{tabular}{|c|c|c|c|}
\hline & $\operatorname{ISR}(+) ; n=27(11.2 \%)$ & ISR (-); n = $214(88.8 \%)$ & $\mathbf{P}$ \\
\hline Multivessel disease & $9(33.3 \%)$ & $49(22.9 \%)$ & 0.104 \\
\hline Treated vessel: & & & 0.783 \\
\hline LAD & $13(48.1 \%)$ & $124(57.9 \%)$ & \\
\hline LCX & $7(26.0 \%)$ & $32(15.0 \%)$ & \\
\hline RCA & $6(22.2 \%)$ & $47(22.0 \%)$ & \\
\hline LMT & $1(3.7 \%)$ & $9(4.2 \%)$ & \\
\hline Stents type: & & & 0.111 \\
\hline Cypher & $4(14.8 \%)$ & $103(48.1 \%)$ & \\
\hline Taxus & $5(18.5 \%)$ & $37(17.3 \%)$ & \\
\hline Endeavor Resolute & $5(18.5 \%)$ & $32(15.0 \%)$ & \\
\hline Pico Elite & $5(18.5 \%)$ & $33(15.4 \%)$ & \\
\hline Stent length [mm] & $23 \pm 6$ & $23 \pm 5$ & 0.449 \\
\hline Stent diameter [mm] & $3.1 \pm 0.5$ & $3.3 \pm 1.7$ & 0.498 \\
\hline
\end{tabular}

ISR — in-stent restenosis; LAD — left anterior descending coronary artery; LCX — left circumflex coronary artery; RCA — right coronary artery; LMT — left main trunk

Table 3. Baseline grayscale intravascular ultrasound findings.

\begin{tabular}{lccc}
\hline & ISR (+); $\mathbf{n}=\mathbf{2 7}(\mathbf{1 1 . 2} \%)$ & ISR $(-) ; \mathbf{n}=\mathbf{2 1 4}(\mathbf{8 8 . 8 \% )}$ & $\mathbf{P}$ \\
\hline Lesion length $[\mathrm{mm}]$ & $16.4 \pm 7.1$ & $19.1 \pm 7.9$ & 0.096 \\
Remodeling index & $0.97 \pm 0.18$ & $0.98 \pm 0.19$ & 0.692 \\
$\quad$ Volumetric analysis $\left[\mathrm{mm}^{3}\right]:$ & $100.0 \pm 49.9$ & $116.0 \pm 64.3$ & 0.213 \\
$\quad$ Lumen volume & $250 \pm 136$ & $294 \pm 170$ & 0.205 \\
$\quad$ Vessel volume & $150 \pm 93$ & $178 \pm 112$ & 0.219 \\
$\quad$ Plaque volume & & & \\
Lesion analysis at MLA $\left[\mathrm{mm}^{2}\right]:$ & $4.16 \pm 1.38$ & $3.86 \pm 1.18$ & 0.224 \\
$\quad$ Lumen area & $14.7 \pm 4.6$ & $15.2 \pm 5.7$ & 0.640 \\
Vessel area $\left[\mathrm{mm}^{2}\right]$ & $10.5 \pm 4.0$ & $11.4 \pm 5.2$ & 0.396 \\
\hline Plaque area $\left[\mathrm{mm}^{2}\right]$ & & & \\
\hline
\end{tabular}

ISR — in-stent restenosis; MLA — minimal luminal area

Pathogenesis of atherosclerosis includes foam cell accumulation in the smooth muscle and endothelial cell layers after oxidation of low-density lipoprotein cholesterol by macrophages. This pathogenesis is associated with inflammatory reactions, and the death of these foam cells ultimately causes necrotic core formation [17].

Therefore, it was hypothesized that the inflammatory coronary plaque composition, such as necrotic core and lipid component in this study, may be associated with ISR development. However, this study did not reveal any significant associations between coronary plaque composition and ISR development. The inflammatory atherosclerotic process can occur naturally after coronary stenting due to increased mechanical and biological stress-induced smooth muscle cell proliferation and neointimal hyperplasia. Thus, inflammation after coronary stenting could be more important than prior plaque composition in terms of ISR. For this reason, the baseline necrotic core volume and/ /or fibrofatty component were not correlated with ISR in the multivariate analysis of this study.

A previous study revealed that old age is an etiology of ISR [18]. In this study, ISR occurred in almost twice as many patients who were over 75 years old than in patients under 75 years old $(\mathrm{p}<0.001)$ and this result was explained by lower ejection frac- 
Table 4. Baseline virtual histology-intravascular ultrasound findings.

\begin{tabular}{|c|c|c|c|}
\hline & ISR (+); n = $27(11.2 \%)$ & ISR (-); n = $214(88.8 \%)$ & $\mathbf{P}$ \\
\hline \multicolumn{4}{|l|}{ Volumetric analysis: } \\
\hline Fibrous $\left[\mathrm{mm}^{3}\right]$ & $58.4 \pm 44.3$ & $67.1 \pm 52.2$ & 0.406 \\
\hline Fibrofatty $\left[\mathrm{mm}^{3}\right]$ & $16.0 \pm 18.2$ & $15.6 \pm 18.0$ & 0.897 \\
\hline Dense calcium $\left[\mathrm{mm}^{3}\right]$ & $7.8 \pm 8.7$ & $9.9 \pm 9.5$ & 0.276 \\
\hline Necrotic core $\left[\mathrm{mm}^{3}\right]$ & $14.2 \pm 12.7$ & $22.1 \pm 19.9$ & 0.045 \\
\hline Fibrous [\%] & $61.5 \pm 9.8$ & $58.8 \pm 10.2$ & 0.194 \\
\hline Fibrofatty [\%] & $16.6 \pm 9.7$ & $12.4 \pm 8.4$ & 0.018 \\
\hline Dense calcium [\%] & $7.8 \pm 6.6$ & $9.3 \pm 6.5$ & 0.242 \\
\hline Necrotic core [\%] & $14.3 \pm 8.7$ & $19.5 \pm 9.1$ & 0.005 \\
\hline \multicolumn{4}{|l|}{ Lesion analysis at MLA: } \\
\hline Fibrous $\left[\mathrm{mm}^{2}\right]$ & $4.6 \pm 2.6$ & $4.8 \pm 2.9$ & 0.675 \\
\hline Fibrofatty $\left[\mathrm{mm}^{2}\right]$ & $1.3 \pm 1.1$ & $1.2 \pm 1.6$ & 0.919 \\
\hline Dense calcium $\left[\mathrm{mm}^{2}\right]$ & $0.4 \pm 0.3$ & $0.6 \pm 0.6$ & 0.081 \\
\hline Necrotic core $\left[\mathrm{mm}^{2}\right]$ & $1.1 \pm 0.8$ & $1.6 \pm 1.3$ & 0.059 \\
\hline Fibrous [\%] & $61.6 \pm 10.5$ & $58.3 \pm 14.3$ & 0.244 \\
\hline Fibrofatty [\%] & $16.7 \pm 10.8$ & $12.7 \pm 11.2$ & 0.090 \\
\hline Dense calcium [\%] & $6.1 \pm 5.2$ & $8.9 \pm 9.9$ & 0.159 \\
\hline Necrotic core [\%] & $15.8 \pm 10.2$ & $20.0 \pm 11.1$ & 0.064 \\
\hline Lesion type: & & & 0.015 \\
\hline Pathologic intimal thickening & $1(3.7 \%)$ & $15(7.0 \%)$ & \\
\hline Fibrocalcific atheroma & $10(37.0 \%)$ & $34(15.9 \%)$ & \\
\hline Fibrous cap atheroma & $8(30.0 \%)$ & $51(23.8 \%)$ & \\
\hline Thin cap fibroatheroma & $5(18.5 \%)$ & $103(48.1 \%)$ & \\
\hline Unclassified & $2(7.4 \%)$ & $8(3.7 \%)$ & \\
\hline
\end{tabular}

ISR, in-stent restenosis; MLA — minimal luminal area

Table 5. Independent predictors for in-stent restenosis.

\begin{tabular}{lccc}
\hline & $\begin{array}{c}\text { Odds } \\
\text { ratio }\end{array}$ & $\begin{array}{c}\text { 95\% confidence } \\
\text { interval }\end{array}$ & $\mathbf{P}$ \\
\hline Age & 3.557 & $1.242-10.192$ & 0.018 \\
hs-CRP & 3.334 & $1.158-9.596$ & 0.026 \\
$\% \mathrm{NCV}$ & 0.430 & $0.121-1.530$ & 0.193 \\
$\% \mathrm{FFV}$ & 1.175 & $0.328-4.207$ & 0.804 \\
Beta-blockers & 0.364 & $0.100-1.331$ & 0.127 \\
\hline
\end{tabular}

This multivariate analysis included age, hs-CRP, beta-blockers, \% NCV and \% FFV as variables; hs-CRP - high-sensitivity C-reactive protein; $\mathrm{NCV}$ - necrotic core volume; FFV - fibrofatty volume

tions, more unstable angina, higher angina class, more ostial lesions, multivessel disease, calcified lesions and complex lesions observed in older patients. This finding is consistent with this study.
The inflammatory marker hs-CRP is known to be associated with ISR; this was also shown in our study. The increased baseline levels of acute-phase proteins are a marker for hyperresponsiveness of the inflammatory system to nonspecific stimuli [19]. After acute injury, the inflammatory response begins with vascular wall penetration of leukocytes followed by smooth muscle cell migration and hyperplasia. Finally, these processes lead to excessive neointimal hyperplasia [20]. Therefore, increased hs-CRP reflects an exaggerated response to coronary stenting and is thus is correlated with ISR in this study, whereas higher inflammatory coronary plaque composition was not.

There were several limitations in this study. At first, follow-up CAG was performed usually 9 months after PCI. This could not evaluate the ISR due to neo-atheroslcerosis, which can occur very late after stenting. Secondly, we did not evaluate post-stent IVUS and follow up IVUS examination. 
This information would be important to reveal possible stent underexpansion, which is an important factor of ISR. However, we would like to suggest the plaque component regarding ISR, not the stent underexpansion and/or stent edge problems.

\section{Conclusions}

In-stent restenosis was not associated with baseline coronary plaque composition but was associated with old age and increased expression of the inflammatory marker hs-CRP in this study. The present results suggest that the older groups that have increased hs-CRP expression tend to have higher ISR rates; therefore, these groups should exhibit better clinical outcomes with proper angioplasty and appropriate medication, such as anti-inflammatory drugs.

\section{Conflict of interest: None declared}

\section{References}

1. Moses JW, Leon MB, Popma JJ, et al. Sirolimus-eluting stents versus standard stents in patients with stenosis in a native coronary artery. N Engl J Med. 2003; 349(14): 1315-1323, doi: 10.1056/NEJMoa035071, indexed in Pubmed: 14523139.

2. Stettler C, Wandel S, Allemann S, et al. Outcomes associated with drug-eluting and bare-metal stents: a collaborative network meta-analysis. Lancet. 2007; 370(9591): 937-948, doi: 10.1016/ S0140-6736(07)61444-5, indexed in Pubmed: 17869634.

3. Sabaté M, Jiménez-Quevedo P, Angiolillo DJ, et al. DIABETES Investigators. Randomized comparison of sirolimus-eluting stent versus standard stent for percutaneous coronary revascularization in diabetic patients: the diabetes and sirolimus-eluting stent (DIABETES) trial. Circulation. 2005; 112(14): 2175-2183, doi: 10.1161/CIRCULATIONAHA.105.562421, indexed in Pubmed: 16203930.

4. Stone GW, Ellis SG, Cannon L, et al. Comparison of a polymer-based paclitaxel-eluting stent with a bare metal stent in patients with complex coronary artery disease: a randomized controlled trial. JAMA. 2005; 294(10): 1215-1223, doi: 10.1001/ jama.294.10.1215, indexed in Pubmed: 16160130.

5. Cosgrave J, Agostoni P, Ge L, et al. Clinical outcome following aleatory implantation of paclitaxel-eluting or sirolimus-eluting stents in complex coronary lesions. Am J Cardiol. 2005; 96(12): 1663-1668, doi: 10.1016/j.amjcard.2005.07.082, indexed in Pubmed: 16360354 .

6. Dangas GD, Claessen BE, Caixeta A, et al. In-stent restenosis in the drug-eluting stent era. J Am Coll Cardiol. 2010; 56(23): 1897-1907, doi: 10.1016/j.jacc.2010.07.028, indexed in Pubmed: 21109112.

7. Costa MA, Simon DI. Molecular basis of restenosis and drug-eluting stents. Circulation. 2005; 111(17): 2257-2273, doi: 10.1161/01.CIR.0000163587.36485.A7, indexed in Pubmed: 15867193 .
8. Rogers C, Welt FG, Karnovsky MJ, et al. Monocyte recruitment and neointimal hyperplasia in rabbits. Coupled inhibitory effects of heparin. Arterioscler Thromb Vasc Biol. 1996; 16(10): 1312-1318, indexed in Pubmed: 8857930.

9. Teirstein PS, Massullo V, Jani S, et al. Catheter-based radiotherapy to inhibit restenosis after coronary stenting. N Engl J Med. 1997; 336(24): 1697-1703, doi: 10.1056/NEJM199706123362402, indexed in Pubmed: 9180087.

10. Stone GW, Kandzari DE, Mehran R, et al. Percutaneous recanalization of chronically occluded coronary arteries: a consensus document: part I. Circulation. 2005; 112(15): 2364-2372, doi: 10.1161/CIRCULATIONAHA.104.481283, indexed in Pubmed: 16216980 .

11. Mintz GS, Nissen SE, Anderson WD, et al. American College of Cardiology Clinical Expert Consensus Document on Standards for Acquisition, Measurement and Reporting of Intravascular Ultrasound Studies (IVUS). A report of the American College of Cardiology Task Force on Clinical Expert Consensus Documents. J Am Coll Cardiol. 2001; 37(5): 1478-1492, indexed in Pubmed: 11300468.

12. Lee CS, Seo YH, Yang DJu, et al. Positive Vascular Remodeling in Culprit Coronary Lesion is Associated With Plaque Composition: An Intravascular Ultrasound-Virtual Histology Study. Korean Circ J. 2012; 42(11): 747-752, doi: 10.4070/kcj.2012.42.11.747, indexed in Pubmed: 23236326.

13. Sakakura K, Nakano M, Otsuka F, et al. Comparison of pathology of chronic total occlusion with and without coronary artery bypass graft. Eur Heart J. 2014; 35(25): 1683-1693, doi: 10.1093/ eurheartj/eht422, indexed in Pubmed: 24126875.

14. Karas SP, Gravanis MB, Santoian EC, et al. Coronary intimal proliferation after balloon injury and stenting in swine: an animal model of restenosis. J Am Coll Cardiol. 1992; 20(2): 467-474, indexed in Pubmed: 1634687.

15. Toutouzas K, Colombo A, Stefanadis C. Inflammation and restenosis after percutaneous coronary interventions. Eur Heart J. 2004; 25(19): 1679-1687, doi: 10.1016/j.ehj.2004.06.011, indexed in Pubmed: 15451145.

16. Meuwissen M, Piek JJ, van der Wal AC, et al. Recurrent unstable angina after directional coronary atherectomy is related to the extent of initial coronary plaque inflammation. J Am Coll Cardiol. 2001; 37(5): 1271-1276, indexed in Pubmed: 11300434.

17. Libby P. Inflammation in Atherosclerosis. Arterioscler Thromb Vasc Biol. 2012; 32(9): 2045-2051, doi: 10.1161/atvbaha.108. 179705.

18. De Gregorio J, Kobayashi Y, Albiero R, et al. Coronary artery stenting in the elderly: short-term outcome and long-term angiographic and clinical follow-up. J Am Coll Cardiol. 1998; 32(3): 577-583, doi: 10.1016/s0735-1097(98)00287-3.

19. Liuzzo G, Buffon A, Biasucci LM, et al. Enhanced inflammatory response to coronary angioplasty in patients with severe unstable angina. Circulation. 1998; 98(22): 2370-2376, indexed in Pubmed: 9832480.

20. Lasave LI, Abizaid AAC, Paiva e Maia J, et al. [Relationship between plasma C-reactive protein level and neointimal hyperplasia volume in patients with zotarolimus-eluting stents. Volumetric analysis by three-dimensional intracoronary ultrasound]. Rev Esp Cardiol. 2007; 60(9): 923-931, indexed in Pubmed: 17915148 . 